\title{
Adenovirus Type 37 Uses Sialic Acid as a Cellular Receptor on Chang C Cells
}

\author{
Niklas Arnberg, ${ }^{1 *}$ Patricia Pring-Åkerblom, ${ }^{2}$ and Göran Wadell ${ }^{1}$ \\ Department of Virology, University of Umeå, SE-901 85 Umeå, Sweden, ${ }^{1}$ and Institut fur Virologie und Seuchenhygiene, \\ Medizinische Hochschule Hannover, 30623 Hannover, Germany ${ }^{2}$
}

Received 19 March 2002/Accepted 4 June 2002

\begin{abstract}
Epidemic keratoconjunctivitis (EKC) is a severe eye infection caused mainly by adenovirus type 8 (Ad8), Ad19, and Ad37. We have shown that the EKC-causing adenoviruses use sialic acid as a cellular receptor on A549 cells instead of the coxsackie-adenovirus receptor, which is used by most adenoviruses. Recently, Wu et al. (Virology 279:78-89, 2001) proposed that Ad37 uses a 50-kDa protein as a receptor on Chang C conjunctival cells and that this interaction is independent of sialic acid. According to the American Type Culture Collection, this cell line carries HeLa cell markers and should be considered to be a genital cell line. This prompted us to investigate the function of sialic acid as a cellular receptor for Ad37 in Chang C cells. In this study, we demonstrate that enzymatic removal or lectin-mediated blocking of cell surface sialic acid inhibits the binding of Ad37 virions to Chang $C$ cells, as does soluble, virion-interacting sialic acid-containing substances. The binding was $\mathrm{Ca}^{2+}$ or $\mathrm{Mg}^{2+}$ ion independent and mediated by the knob domain of the trimeric viral fiber polypeptide. Moreover, Ad37 virions infected Chang $\mathrm{C}$ cells and two other genital cell lines (HeLa and SiHa) as well as a corneal cell line in a strictly sialic acid-dependent manner. From these results, we conclude that Ad37 uses sialic acid as a major receptor in cell lines derived from both genital and corneal tissues.
\end{abstract}

The human adenovirus group consists of 51 known serotypes which can be divided into six species, designated A through $\mathrm{F}$ $(9,16,30,36)$. Human adenoviruses are associated with gastrointestinal infections (species $\mathrm{F}$ primarily) and respiratory infections (members of species B, C, and E) and are also responsible for most cases of virus-caused ocular infections (members of species B, D, and E) (33). A limited number of species D adenoviruses (i.e., adenovirus type 8 [Ad8], Ad19, and Ad37) are frequently isolated from patients suffering from an ocular disease designated epidemic keratoconjunctivitis $(\mathrm{EKC})$. This is a relatively severe virus-caused eye infection involving both the conjunctiva and the cornea $(18,19)$. Epidemiologically, Ad8 was the main causative agent of EKC until 1973, when Ad19a emerged (23). Outbreaks of Ad19-associated EKC have been reported (20). These infections were caused by Ad19a, an emerging genome type distinct from the Ad19 prototype virus (35). In contrast to Ad19a, the prototype virus (Ad19p) has been isolated only once according to the literature, in Saudi Arabia in 1955, and was not associated with EKC (8). Ad37 emerged in 1976, and like Ad19a, it was also found to cause EKC (17). Both Ad19a and Ad37 have been associated with sexually transmitted genital disease $(25,31)$, and even eye infections appear to be transmitted through direct contact (7).

Most, but not all, adenoviruses attach to host cells through an interaction between the knob domain of the viral fiber polypeptide and the cell surface coxsackie-adenovirus receptor (CAR) $(10,27,32)$. The length of the fiber is determined by the specific number of repetitive motifs in the shaft, which varies from 6 motifs (species B) to 22 motifs (species A, C, and

\footnotetext{
* Corresponding author. Mailing address: Department of Virology, University of Umeå, SE-901 85 Umeå, Sweden. Phone: 46907852891. Fax: 469012 9905. E-mail: niklas.arnberg@climi.umu.se.
}

F). Fiber length has been reported to play a crucial role in interactions with CAR (29). Consequently, adenoviruses from all species except those of species B, which have the shortest fibers, have been found to interact with CAR (27). Species D adenoviruses have fibers of intermediate length, and at least two serotypes from species D, Ad9 and Ad19p, have been shown to interact with soluble CAR, albeit with a much lower affinity compared to the fibers of Ad5 (species C) $(24,27)$. The knob domains of Ad5 and Ad12 (of species A) have been thoroughly investigated by X-ray crystallography and mutational studies, demonstrating that the CAR-interacting region maps to the $\mathrm{AB}$ loop $(11,28)$. A CAR-interacting motif has been localized in adenoviruses from all species, including Ad37, but not in species B adenoviruses (11). Despite the apparent presence of a CAR-interacting motif, Ad37 does not attach to CAR-positive cells more efficiently than to their CAR-negative equivalents (5).

Although CAR appears to be the major adenovirus receptor, other components such as major histocompatibility complex class I- $\alpha 2$ (21), heparan sulfate $(13,14)$, and VCAM-1 (12) have been reported to serve as potential adenovirus receptors or coreceptors. Recently, it was found that Ad37 is able to use $\alpha(2-3)$-linked sialic acid as a functional first-step receptor on A549 cells (5). It was also found that Ad8 and Ad19a, which has a fiber protein identical to that of $\mathrm{Ad} 37$, also use sialic acid as a functional receptor, whereas the closely related Ad9 and Ad19p and the distantly related Ad5 do not use sialic acid as a major receptor $(4,5)$. Thus, the ability of Ad8, Ad19a, and $\mathrm{Ad} 37$ to use sialic acid as a cellular receptor is unusual among the human adenoviruses and may be closely linked to their unique ability to cause EKC.

It was recently demonstrated that $\mathrm{Ad} 37$ interacts with a subcategory of the HeLa cell line designated Chang $\mathrm{C}$ more efficiently than does Ad19p and that this was due to one single 
amino acid substitution in the fiber knob (22). Moreover, the same authors proposed subsequently that the Chang C cells, which were incorrectly referred to as conjunctival (http://www .atcc.org), expressed a 50-kDa membrane protein which mediated sialic acid-independent binding and infection by Ad37 (37). Here, we demonstrate that $\operatorname{Ad} 37$ uses sialic acid as a functional, first-step receptor on Chang $\mathrm{C}$ cells and on two other genital cell lines (HeLa and $\mathrm{SiHa}$ ), as well as on human corneal epithelial (HCE) cells.

\section{MATERIALS AND METHODS}

Cells and viruses. Chang $\mathrm{C}, \mathrm{HeLa}$, and $\mathrm{SiHa}$ cells were grown as monolayers in Dulbecco's modified Eagle's medium (Sigma Chemical Co., St. Louis, Mo.) supplemented with $10 \%$ fetal calf serum (FCS), HEPES, and penicillin-streptomycin (all from Sigma). HCE cells were grown as monolayers in steroid hormone epithelial medium as described previously (2). The correct identities of Ad5 (strain Adenoid 75), Ad8 (strain Trim), Ad19p (strain 587), and Ad37 (strain 1477) were ascertained by restriction enzyme analysis (1). Virions of corresponding strains were then ${ }^{35}$ S-labeled with Promix (Amersham Pharmacia Biotech, Uppsala, Sweden) as described previously (15). The specific radioactivity levels expressed as counts per minute per virion for Ad5, Ad8, Ad19p, and Ad37 were $2.4 \times 10^{-5}, 10^{-5}, 1.3 \times 10^{-5}$, and $10^{-5}$, respectively.

Virion binding assays. All cells were harvested with phosphate-buffered saline (PBS)-EDTA only, and all binding and binding inhibition assays were carried out in triplicate at $100 \mu \mathrm{l} /$ sample with ${ }^{35} \mathrm{~S}$-labeled virions.

Effect of neuraminidase on the binding of adenoviruses to Chang $\mathbf{C}$ cells. Prior to the addition of $100 \mu \mathrm{l}$ of neuraminidase, $2 \times 10^{5}$ Chang $\mathrm{C}$ cells were washed in PBS containing 2\% FCS. Neuraminidase from Vibrio cholerae (Sigma) was diluted in PBS containing $2 \%$ FCS, added to cell pellets, mixed, and incubated at $37^{\circ} \mathrm{C}$. After $1 \mathrm{~h}$, the cells were washed twice in binding buffer (BB; Dulbecco's modified Eagle's medium containing $1 \%$ bovine serum albumin [BSA]). Ad8 or Ad37 virions were added to the cells $\left(10^{5}\right.$ virions/cell $)$, mixed, and incubated on ice for $1 \mathrm{~h}$. Finally, the cells were washed twice in BB and resuspended in $100 \mu \mathrm{l}$ of BB. Two milliliters of scintillation fluid was added, and cell-associated radioactivity was counted with a Wallac 1409 scintillation counter.

Inhibition of Ad37 binding to Chang $\mathrm{C}$ cells by rabbit polyclonal anti-fiber knob serum. Chang $\mathrm{C}$ cells at a concentration of $2 \times 10^{5}$ cells/sample were resuspended in $\mathrm{BB}$ with ${ }^{35} \mathrm{~S}$-labeled $\mathrm{Ad} 37$ virions corresponding to $10^{5}$ virions/ cell and with rabbit polyclonal anti-Ad37 knob serum or preimmune serum at different dilutions. The mixture was incubated on ice for $1 \mathrm{~h}$ and washed twice in BB. The cell-associated radioactivity was measured as described above.

Scatchard analysis. Chang $\mathrm{C}$ cells at a concentration of $1 \times 10^{5}$ cells/sample were incubated with increasing amounts of ${ }^{35}$ S-labeled Ad37 virions in $100 \mu \mathrm{l}$ of PBS containing $2 \% \mathrm{FCS}$ at $4^{\circ} \mathrm{C}$ and under constant agitation. Unbound virions were removed by washing. Nonspecific binding was determined by treating cell samples with $20 \mathrm{mU}$ of $V$. cholerae neuraminidase/sample. Radioactivity from cell and wash fractions was measured separately as described above. Nonspecific binding was subtracted from total binding prior to Scatchard analysis, which was performed by the Prism program (Graphpad Software Inc., San Diego, Calif.).

Effect of lectins on the binding of Ad5 and Ad37 to Chang $\mathrm{C}$ cells. The lectins from Triticum vulgaris (wheat germ agglutinin [WGA]; Sigma), Sambucus nigra (Sambucus nigra agglutinin [SNA]; Sigma), or Maackia amurensis (Maackia amurensis agglutinin [MAA]; Sigma) at a concentration of $0.5 \mathrm{mg} / \mathrm{ml}$ each were dissolved in $\mathrm{BB}$ and added to $2 \times 10^{5}$ prewashed Chang $\mathrm{C}$ cells. The cells were incubated on ice for $1 \mathrm{~h}$, and $10^{5} \mathrm{Ad} 5$ or Ad37 virions/cell were added. After another hour on ice, the cells were washed, pelleted, and resuspended in $100 \mu \mathrm{l}$ of BB. Scintillation fluid was added, and the cell-associated radioactivity was counted as described above.

Effect of divalent cations during the binding of Ad37 to Chang $\mathbf{C}$ cells. Samples of $2 \times 10^{5}$ Chang $\mathrm{C}$ cells each were incubated on ice with $10^{5}$ virions/cell in 10 $\mathrm{mM}$ Tris- $\mathrm{HCl}$ (pH 7.4) containing $1 \%$ FCS only (control); with 10 mM EDTA; or with 1,2 , or $4 \mathrm{mM} \mathrm{CaCl}_{2}$ or $\mathrm{MgCl}_{2}$. One hour later, the cells were washed twice with Tris- $\mathrm{HCl}(\mathrm{pH} 7.4)$ containing $1 \%$ FCS and the cell-associated radioactivity was measured as described above.

Effect of sialic acid or sialoconjugates on the binding of Ad37 to Chang C cells. Sialylated and nonsialylated saccharides or glycoproteins (all purchased from Sigma) were dissolved in $100 \mu \mathrm{l}$ of $\mathrm{BB} /$ sample and incubated at different concentrations with $2 \times 10^{10} \mathrm{Ad} 37$ virions on ice for $1 \mathrm{~h}$ (as indicated in Tables 1 and 2). Harvested Chang $C$ cells were washed twice in BB. Pelleted cells at a concentration of $2 \times 10^{5} /$ sample were then resuspended with the virion mixture
TABLE 1. Inhibition of Ad37 attachment to Chang $\mathrm{C}$ cells by monosaccharides and oligosaccharides ${ }^{a}$

\begin{tabular}{lrc}
\hline \multicolumn{1}{c}{ Mono- or oligosaccharide } & $\begin{array}{c}\text { Saccharide } \\
\mathrm{ID}_{50} \\
(\mathrm{mM})\end{array}$ & $\begin{array}{c}\text { \% Maximal inhibition } \\
\text { of Ad37 attachment } \\
\text { at 160 mM saccharide }\end{array}$ \\
\hline Galactose & $>160$ & 0 \\
Lactose & $>160$ & 0 \\
Mannose & $>160$ & 0 \\
$N$-Acetylgalactosamine & $>160$ & 15 \\
$N$-Acetyllactosamine & $>160$ & 9 \\
$N$-Acetylmannosamine & 40 & 0 \\
NGNA & 18 & 91 \\
NANA & 7 & 82 \\
$N$-Acetylneuraminylacetyllactosamine & 5 & - \\
$N$-Acetylneuraminylfucosyllactose & 5 & 95 \\
$N$-Acetylneuraminyllactose & & 95 \\
\hline
\end{tabular}

${ }^{a}$ Determined as described in Materials and Methods. Each value represents the mean from three independent experiments.

$b$ - , not determined.

and incubated on ice for $1 \mathrm{~h}$. The cells were washed twice in $\mathrm{BB}$, pelleted, resuspended in $100 \mu \mathrm{l}$ of $\mathrm{BB}$, and mixed with $2 \mathrm{ml}$ of scintillation fluid. Cellbound radioactivity was measured as described above.

Recombinant fiber knobs. Adenovirus DNA was extracted from HeLa cells infected with Ad5, Ad8, Ad19p, or Ad37 as previously described (1). PCR amplification and cloning of fiber knob constructs into pQE32 plasmids (Qiagen, Hilden, Germany) have been described elsewhere (26). His-tagged fiber knobs were expressed in soluble form and purified with Ni-nitrilotriacetic acid agarose according to the instructions of the manufacturer (Qiagen).

Preparation of antisera. The preparation of rabbit antisera directed against purified Ad5 and Ad37 virions has been described previously (34). Recombinant Ad37 knobs were used for the production of rabbit polyclonal anti-knob antibodies (Agrisera AB, Vännäs, Sweden). The rabbits were immunized four times intramuscularly and subcutaneously with $200 \mu \mathrm{g}$ of knob and Freund's complete adjuvant per rabbit or $100 \mu \mathrm{g}$ of knob and Freund's incomplete adjuvant per rabbit with intervals of 2,3 , and 6 weeks between immunizations.

Flow cytometry. Adherent Chang C cells were detached with PBS-EDTA [pH 7.4], washed twice, and resuspended in $\mathrm{BB}$ with or without $20 \mathrm{mU}$ of neuraminidase per $5 \times 10^{5}$ cells. The cells were incubated at $37^{\circ} \mathrm{C}$ for $1 \mathrm{~h}$, washed in $\mathrm{BB}$, and then incubated on ice with $5 \mu \mathrm{g}$ of recombinant fiber knobs diluted in $100 \mu \mathrm{l}$ of BB. One hour later, the cells were washed in BB and incubated on ice, first with mouse anti-His tag antibodies (Qiagen) diluted 1:1,000 in $100 \mu \mathrm{l}$ of BB, and then, after washing, with fluorescein isothiocyanate (FITC)-labeled rabbit antimouse antibodies (Dakopatts, Glostrup, Denmark) diluted 1:100 in $100 \mu \mathrm{l}$ of BB. After washing, 10,000 cells/sample were analyzed by a FACScan (Becton Dickinson, Franklin Lakes, N.J.) with the CellQuest software program (Becton Dickinson).

TABLE 2. Inhibition of Ad37 attachment to Chang $\mathrm{C}$ cells by sialylated glycoproteins ${ }^{a}$

\begin{tabular}{lrc}
\hline \multicolumn{1}{c}{ Glycoprotein } & $\begin{array}{c}\text { Glycoprotein } \\
\mathrm{ID}_{50}(\mu \mathrm{M})\end{array}$ & $\begin{array}{c}\text { \% Maximal inhibition of } \\
\text { Ad37 attachment at 500 } \\
\mu \mathrm{M} \text { glycoprotein }\end{array}$ \\
\hline BSA $^{b}$ & $>500$ & 0 \\
Fetuin $^{d}$ & 420 & 62 \\
Asialofetuin & $>500$ & 10 \\
Mucin $^{c}$ & 8 & 89 \\
Asialomucin & $>500$ & 0 \\
Orosomucoid & 75 & 77 \\
Glycophorin A & $>500$ & 45 \\
\hline
\end{tabular}

${ }^{a}$ Determined as described in Materials and Methods. Each value represents the mean from three independent experiments.

${ }^{b}$ BSA, bovine serum albumin.

${ }^{c}$ The molecular mass of mucins has not yet been accurately determined and was estimated here to be $200 \mathrm{kDa}$.

${ }^{d}$ Determined at $3 \mathrm{mM}$. 
Fluorescent focus assay. Adherent Chang C, HCE, HeLa, or SiHa cells at a concentration of $2 \times 10^{5}$ cells/well in 24-well plates were incubated with or without $20 \mathrm{mU}$ of neuraminidase in PBS containing $1 \% \mathrm{FCS}$ for $1 \mathrm{~h}$ at $37^{\circ} \mathrm{C}$. The cells were then chilled and washed twice with cold BB. Ad5 or Ad37 virions were diluted in $\mathrm{BB}$ and added to the cells at concentrations corresponding to 5,000 fluorescent focus units (FFU) per cell type and sample. Hence, the virion dilutions were adjusted so that $100 \mathrm{FFU} /$ viewing field were obtained in the control (nontreated cells). The cells were then incubated on ice, permitting attachment of virions but not internalization. After $1 \mathrm{~h}$, unbound virions were removed by washing with $\mathrm{BB}$. The cells were then incubated at $37^{\circ} \mathrm{C}$ in $\mathrm{BB}$, thus permitting internalization of virions into cells. At $40 \mathrm{~h}$ postinfection, the cells were rinsed in PBS, fixed with $99 \%$ methanol, and incubated at room temperature with rabbit polyclonal anti-Ad5 or anti-Ad37 antibodies diluted 1:200 in PBS containing $0.05 \%$ Tween 20. One hour later, the cells were washed in PBS-Tween 20 and stained for $1 \mathrm{~h}$ at room temperature with FITC-labeled swine anti-rabbit immunoglobulin $G$ antibodies (Dakopatts) diluted 1:200. Finally, the cells were washed as before and examined in an immunofluorescence microscope (Xiovert 25; magnification, $\times 10$; Carl Zeiss, Jena, Germany).

\section{RESULTS}

Ad8 and Ad37 virions use cell surface sialic acid for attachment to Chang $\mathbf{C}$ cells. In our first attempt to investigate the ability of sialic acid to serve as an adenovirus receptor, we treated Chang $\mathrm{C}$ cells with neuraminidase from $V$. cholerae. Both Ad8 and Ad37 virions interacted efficiently with untreated Chang $\mathrm{C}$ cells as compared to Ad19p and Ad5 virions (compare Fig. 1A and B). As much as $20 \%$ of the input Ad8 virions $\left(10^{5}\right.$ virions/cell) remained attached to the cells after incubation and subsequent washing steps, whereas the corresponding figure for $\mathrm{Ad} 37$ was $12.5 \%$. Only $1 \%$ of the input Ad19p virions attached to Chang $\mathrm{C}$ cells, whereas $2.5 \%$ of the input Ad5 virions remained attached to the untreated cells. The binding of Ad5 virions was not reduced as a result of neuraminidase treatment. Instead, the level of attachment was slightly enhanced. On the contrary, this treatment efficiently inhibited the attachment of $\mathrm{Ad} 37$ as well as $\mathrm{Ad} 8$ virions to Chang C cells.

Ad8 and Ad37 fiber knobs attach to Chang $\mathrm{C}$ cells through sialic acid. Most adenoviruses attach to target cells via an interaction between the knob domain of the viral fiber protein and a cellular receptor. In agreement with this, we found that rabbit antiserum raised against the fiber knob of Ad37 efficiently inhibited the attachment of Ad37 virions to Chang C cells (Fig. 2). The attachment was unchanged when preimmune serum was used, indicating that the inhibitory effect of serum was due to function-blocking anti-Ad37 knob antibodies. To investigate whether fiber knobs interact directly with sialic acid on Chang C cells, we developed a flow cytometry assay in which recombinant knobs from multiple adenovirus types were used to measure attachment to Chang $\mathrm{C}$ cells. As expected, fiber knobs from both Ad8 and Ad37 attached efficiently to Chang C cells whereas knobs from Ad5 and Ad19p attached with lower efficiency. Moreover, attachment of Ad8 and Ad37 knobs was almost completely abolished upon pretreatment of Chang $\mathrm{C}$ cells with neuraminidase whereas attachment of Ad5 knobs was unchanged (Fig. 2).

Scatchard analysis of Ad37 virion binding to Chang $\mathrm{C}$ cells. Adenovirus interactions with host cells are mediated by binding of the fiber protein to high-affinity receptors which have been described to vary between 5,000 and 7,000 per cell, depending on the adenovirus types and cell lines investigated (15). Ad37 fibers have been described to interact with Chang C
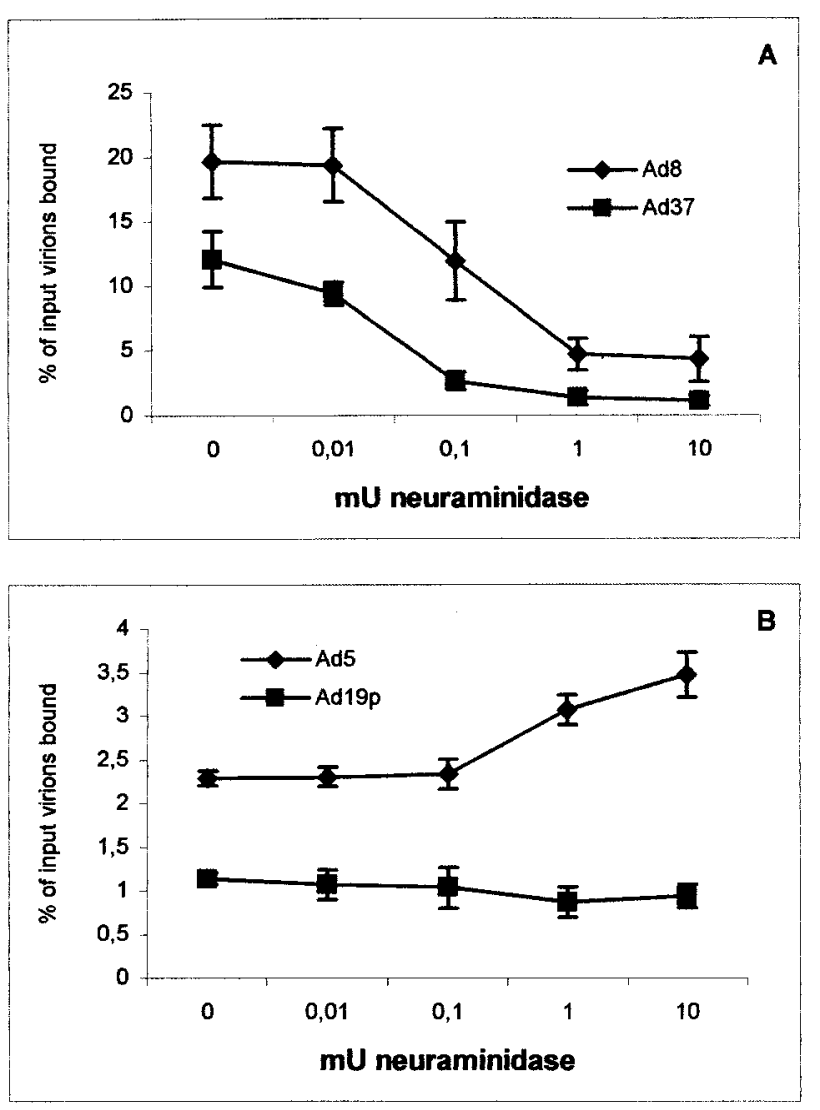

FIG. 1. Enzymatic removal of sialic acid from the surface of Chang $\mathrm{C}$ cells inhibits attachment of $\mathrm{Ad} 8$ and $\mathrm{Ad} 37$ virions. Chang C cells (2 $\times 10^{5}$ ) in suspension were treated with or without neuraminidase and incubated with ${ }^{35}$ S-labeled Ad8 or Ad37 virions (A) or Ad5 or Ad19p virions (B) as described in Materials and Methods. The cell-associated radioactivity was measured and plotted as the amount of virions bound divided by the total number of virions added. The data represent the means from three independent experiments.

cells through numerous $\left(2.4 \times 10^{4} /\right.$ cell $)$ high-affinity receptors (dissociation constant $\left[K_{D}\right]=3.5 \mathrm{nM}$ ). Here, we used Ad37 virions and determined the affinity and receptor number on the same cells by Scatchard analysis (Fig. 3). Whereas the receptor number was of the same order $\left(2.9 \times 10^{4} /\right.$ cell $)$, the affinity was 10 -fold higher $(0.35 \mathrm{nM})$ when using multivalent virions instead of monovalent fibers.

Preincubation of Chang $\mathrm{C}$ cells with sialic acid-blocking lectins inhibits cellular attachment of Ad37. To investigate whether sialic acid-interacting molecules could inhibit attachment of Ad37 to Chang C cells, we preincubated these cells with different types of lectins. WGA interacts with terminal sialic acid saccharides regardless of the type of glycosidic linkage between the sialic acid saccharide and the neighboring saccharide. Here, WGA efficiently blocked the attachment of Ad37 virions to Chang C cells (Fig. 4). The inhibitory effect was apparently specific for Ad37, since the attachment of Ad5 virions to Chang $\mathrm{C}$ cells was not affected. Moreover, it was previously shown that Ad37 interacts primarily with cell surface sialic acid saccharides linked to the neighboring saccharide by an $\alpha$ (2-3)-linked glycosidic bond rather than an $\alpha(2-$ 

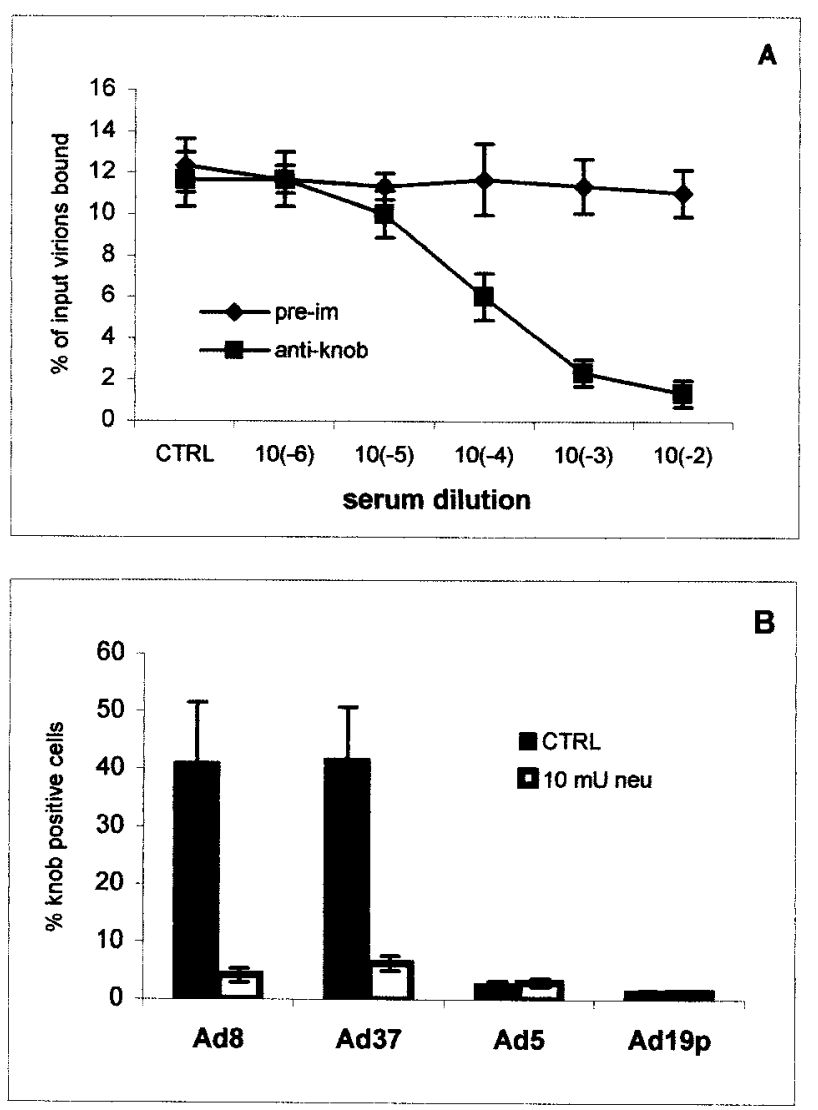

FIG. 2. Ad37 virions attach to the surface of Chang C cells through an interaction between viral fiber knobs and cellular sialic acid. (A) Ad37 virions were prevented from binding to Chang $\mathrm{C}$ cells with polyclonal rabbit antiserum raised against the Ad37 fiber knob. ${ }^{35} \mathrm{~S}$ labeled Ad37 virions were incubated with 10 -fold dilutions of antiserum and then added to $2 \times 10^{5}$ Chang $\mathrm{C}$ cells/sample. Unbound virions were removed by washing, and the cell-associated radioactivity was measured. pre-im, preimmune serum; anti-knob, serum raised against the Ad37 knob. (B) Neuraminidase-treated (neu) or mocktreated (CTRL) Chang C cells were incubated with $5 \mu \mathrm{g}$ of His-tagged recombinant fiber knobs as indicated and subsequently detected with mouse anti-His tag antibodies, followed by FITC-labeled rabbit antimouse antibodies. Cells $\left(10^{4} / \mathrm{sample}\right)$ were counted with a flow cytometer. All data represent the means from three independent experiments.

6)-linked glycosidic bond (5). By preincubating cells with lectins specific for either $\alpha(2-3)$-linked sialic acid (Maackia amurensis lectin) or $\alpha(2-6)$-linked sialic acid (Sambucus nigra lectin), we were able to demonstrate that efficient attachment of Ad37 virions to Chang $\mathrm{C}$ cells prefers cell surface sialic acid linked to its neighboring saccharide via an $\alpha(2-3)$-linked glycosidic bond rather than an $\alpha(2-6)$-linked glycosidic bond.

Sialylated saccharides and glycoproteins inhibit Ad37 virions from binding to Chang $\mathbf{C}$ cells. To investigate whether sialic acid-containing components could inhibit the attachment of Ad37 to Chang C cells, we preincubated Ad37 virions with different types of saccharides or glycoproteins before adding virions to cells. Quite obviously, all non-sialic acid-containing saccharides included here were unable to inhibit attachment of Ad37 even at high concentrations (160 mM [Table 1]). The two

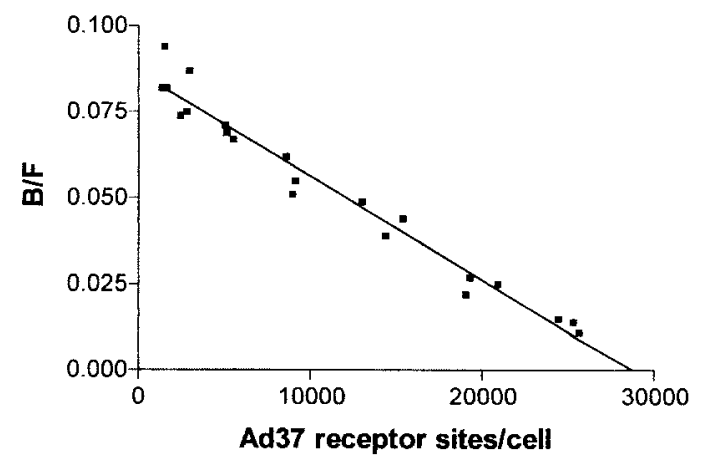

FIG. 3. Scatchard analysis of Ad37 binding to Chang C cells. Increasing amounts of ${ }^{35} \mathrm{~S}$-labeled Ad37 virions were incubated with Chang C cells in suspension as described in Materials and Methods. Ratios of bound (cell-associated) virion radioactivity to free virion radioactivity $(\mathrm{B} / \mathrm{F})$ were plotted against the number of bound virions per cell. The disassociation constant $\left(K_{D}=0.35 \mathrm{nM}\right)$ was derived from the slope of the line. The number of receptor sites for Ad37 virions (2.9 $\times 10^{4}$ ) was derived from the value extrapolated to intercept the abscissa. The data shown were obtained from three separate experiments.

types of the sialic acid monosaccharides analyzed, $\mathrm{N}$-glycolylneuraminic acid (NGNA) and $N$-acetylneuraminic acid (NANA), inhibited $50 \%$ of Ad37 virion binding to Chang $\mathrm{C}$ cells $\left(\mathrm{ID}_{50}\right)$ at $40 \mathrm{mM}$ (NGNA) or $18 \mathrm{mM}$ (NANA), whereas $\mathrm{N}$-acetylneuraminylacetyllactosamine, $\mathrm{N}$-acetylneuraminylfucosyllactose, and $N$-acetylneuraminyllactose inhibited $50 \%$ of Ad37 attachment at 7, 5, and $5 \mathrm{mM}$, respectively. In a similar assay, we investigated the effect of sialylated or desialylated glycoproteins on Ad37 attachment to Chang C cells. All sialic acid-deficient glycoproteins (albumin, asialofetuin, and asialomucin) were inefficient in inhibiting attachment of Ad37, whereas the sialic acid-containing glycoproteins (fetuin, mucin, and orosomucoid) efficiently inhibited attachment (Table 2). In the case of mucin, the impact of sialic acid on the inhibition of attachment was obvious since native mucin inhibited $50 \%$ of Ad37 attachment at $8 \mu \mathrm{M}$ whereas desialylated mucin did not affect attachment at $500 \mu \mathrm{M}$. We also tested various gangliosides for their ability to inhibit binding. At $0.7 \mathrm{mM}$, two gangliosides, GM2 and GT1b, inhibited Ad37 binding to Chang C cells at $27 \%$ and $24 \%$, respectively (Table 3 ). Obviously, even though gangliosides are subordinated glycoproteins as cellular receptors for $\operatorname{Ad} 37$ (5), gangliosides with specific saccharide structures may interfere with binding.

Divalent cations are not required for the attachment of Ad37 virions to Chang $\mathbf{C}$ cells. In order to investigate the involvement of divalent cations during the interaction between Ad37 virions and Chang C cells, we included $10 \mathrm{mM}$ EDTA in the incubation buffer (Tris- $\mathrm{HCl}, \mathrm{pH}$ 7.4) and allowed Ad37 virions to bind to Chang $\mathrm{C}$ cells. We did not see any effect of EDTA on the binding of Ad37 either to Chang $\mathrm{C}$ cells or to HCE cells (Fig. 5), which contradicts the findings of $\mathrm{Wu}$ et al. (37), who proposed that $\mathrm{Ca}^{2+}$ ions but not $\mathrm{Mg}^{2+}$ ions were required for efficient binding of $\mathrm{Ad} 37$ to Chang $\mathrm{C}$ cells. Furthermore, the addition of $\mathrm{Ca}^{2+}$ or $\mathrm{Mg}^{2+}$ to EDTA-treated cells did not affect the binding of $\mathrm{Ad} 37$ at $4^{\circ} \mathrm{C}$.

Cell surface sialic acid is required for Ad37 infection of 

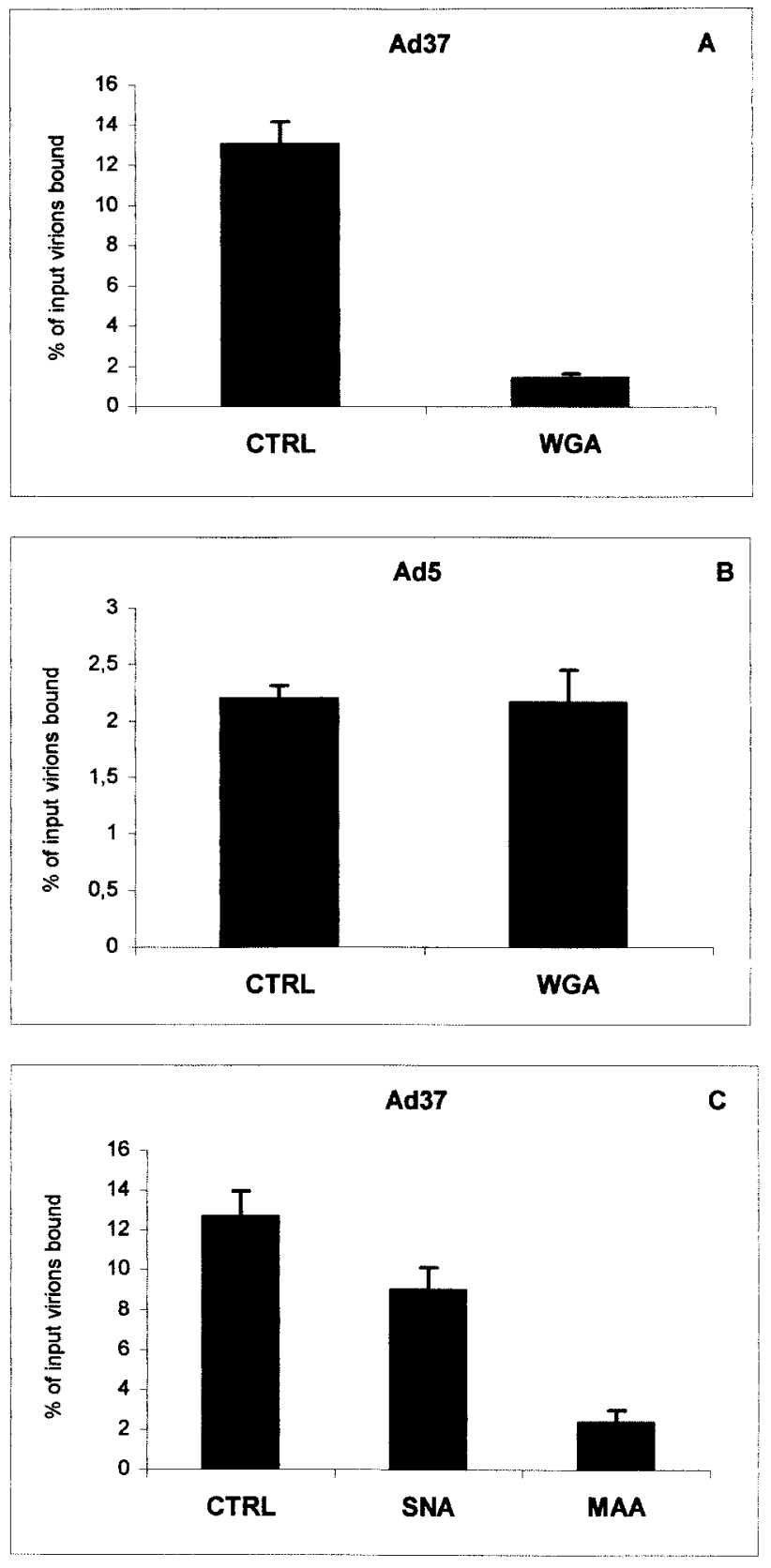

FIG. 4. Sialic acid-interacting lectins inhibit attachment of adenoviruses to Chang $\mathrm{C}$ cells in a glycosidic bond-specific and serotypespecific manner. Chang C cells $\left(2 \times 10^{5}\right)$ were preincubated with WGA, SNA, or MAA and then further incubated with one of the following ${ }^{35}$ S-labeled virions: A and C, Ad37; B, Ad5. Unbound virions were removed by washing, and the cell-associated radioactivity was measured. All data represent the means from three independent experiments. CTRL, control.

Chang C, HeLa, SiHa, and HCE cells. Wu et al. reported that the binding of the Ad37 fiber protein to cellular sialic acid is not necessary for infection of Chang $C$ cells (37). In order to investigate the effect of neuraminidase treatment on $\mathrm{Ad} 37$ infection of Chang $\mathrm{C}$ cells, we used an infectivity assay that visualizes adenovirus-infected cells as FFU. Here, we demon-
TABLE 3. Effect of sialylated glycolipids on Ad37 attachment to Chang C cells

Glycolipid ${ }^{a}$
GM1 $\begin{gathered}\% \text { Maximal inhibition }{ }^{c} \text { of } \\ \text { Ad37 attachment at } 0.7 \\ \text { mM saccharide }\end{gathered}$

${ }^{a}$ Monosialylated (M), disialylated (D), or trisialylated (T) gangliosides.

${ }^{b}$ Disialylated phosphatidylethanolamine.

${ }^{c}$ Determined as described in Materials and Methods. Each value represents the mean from three independent experiments.

strated that the reference adenovirus (Ad5) infected neuraminidase-treated cells from the genital tract (Chang $\mathrm{C}, \mathrm{HeLa}$, and $\mathrm{SiHa}$ ) or the cornea (HCE) twice as efficiently as mocktreated cells. This has been reported before with A549 cells and has been suggested to depend on a decrease in chargedependent repulsion between the cell surface and the acidic Ad5 capsid (3). This effect was not achieved with Ad37. Instead, neuraminidase treatment of the same cell lines protected 90 to $99 \%$ of the cells from being infected by Ad37 (Fig. $6)$, which supports the results obtained from the binding experiments, showing that sialic acid can serve as a cellular receptor for Ad37 on epithelial cells of genital as well as corneal origin.

\section{DISCUSSION}

In this study, we have examined the role of sialic acid as a cellular receptor for Ad37 on Chang C cells. Together with Ad8 and Ad19a, Ad37 is responsible for the majority of EKC cases worldwide. It was previously shown that Ad8, Ad19a, and Ad37 use sialic acid as a functional receptor on A549 cells, whereas the closely related Ad9 and Ad19p (both also of species D) do not (4). Consequently, there is a clear correlation between the ability of these adenoviruses to use sialic acid as a receptor and their tropism. The finding that sialic acid acts as an adenovirus receptor is of importance in understanding the life cycle and tropism of ocular adenoviruses. Furthermore, no functional antiviral compounds are currently available against the EKC-causing adenoviruses and this finding may contribute to the development of such antiviral agents. Therefore, the recent suggestion by $\mathrm{Wu}$ et al. (37) that sialic acid is not a receptor for Ad37 on Chang $\mathrm{C}$ conjunctival cells, which, according to the American Type Culture Collection is a HeLa marker-expressing cell line, prompted us to investigate the role of sialic acid as a cellular receptor for $\mathrm{Ad} 37$ on epithelial cells of both genital and ocular (corneal) origin.

Neuraminidase treatment of Chang $\mathrm{C}$ cells efficiently inhibited the attachment of both Ad8 and Ad37 virions. This interaction is most likely mediated by the fibers of Ad8 and Ad37, since we found here that $\operatorname{Ad} 8$ and $\mathrm{Ad} 37$ knobs attached to Chang $\mathrm{C}$ cells in a sialic acid-dependent fashion and with equal efficiency. Since Ad37 and Ad19a have identical fibers (6), it is likely that all three EKC-causing adenoviruses use sialic acid as 

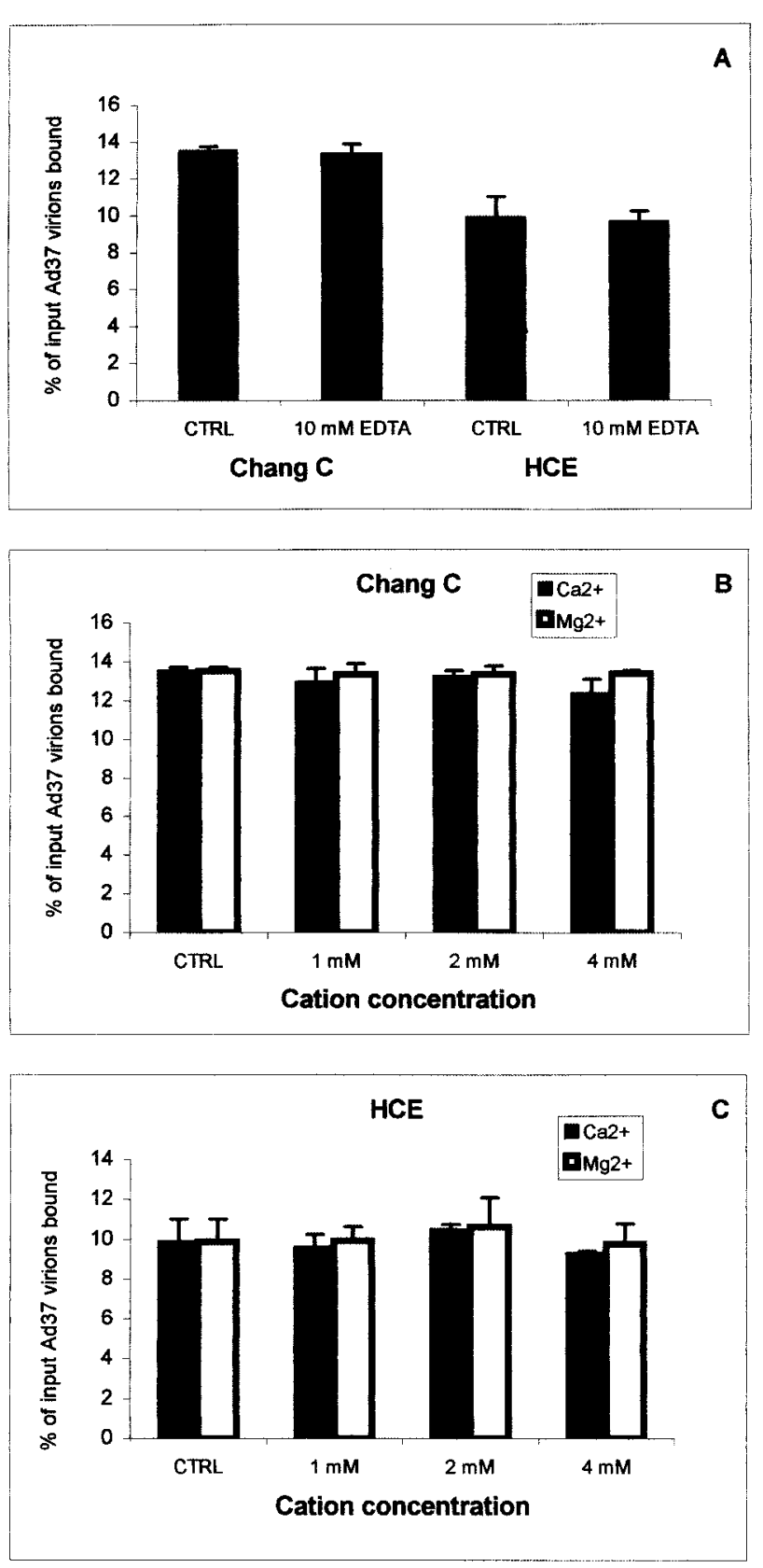

FIG. 5. Ad37 virions do not require divalent cations for attachment to Chang $\mathrm{C}$ or $\mathrm{HCE}$ cells. Chang $\mathrm{C}$ or $\mathrm{HCE}$ cells were incubated on ice with ${ }^{35}$ S-labeled Ad37 virions in Tris- $\mathrm{HCl}(\mathrm{pH} 7.4)$ containing $1 \%$ FCS and 10 mM EDTA (A) or various concentrations of $\mathrm{CaCl}_{2}$ or $\mathrm{MgCl}_{2}(\mathrm{~B}$ and $\mathrm{C}$ ). Unbound virions were removed by washing, and cell-associated radioactivity was measured. The data represent the means from three independent experiments. CTRL, control.

a receptor on Chang $\mathrm{C}$ cells. Ad19p is slightly different from Ad37 (and Ad19a) in the fiber and does not share a receptor with Ad37 on Chang C cells (22). In agreement with this, Ad19p and Ad5 attached to Chang $\mathrm{C}$ cells in a sialic acidindependent fashion. The $K_{D}$ describing the interaction between Ad37 fibers and Chang C cells has been calculated to be $3.5 \mathrm{nM}$ (22). Here, we calculated the $K_{D}$ between Ad37 virions and the same cells to be $0.35 \mathrm{nM}$. This affinity is stronger and is probably due to binding by more than one fiber per virion. On the other hand, the receptor numbers obtained with fibers or virions were in the same order $\left(2.9 \times 10^{4}\right.$ versus $2.4 \times 10^{4}$, respectively) and can be compared with the CAR-interacting Ad5, which binds to only 5,000 receptors per A549 cell (15). This would at least partially explain the relatively low binding efficiency obtained with Ad5 virions or fiber knobs in this study. In addition, it was shown by Gall et al. that $\mathrm{Ad} 5$ binds to host cells at least 10 -fold better at $37^{\circ} \mathrm{C}$ than at $4^{\circ} \mathrm{C}(18 \mathrm{a})$. Our binding experiments were performed at $4^{\circ} \mathrm{C}$ (in order to avoid internalization), which may have also contributed to the relatively low binding by Ad5.

Lectins are proteins or glycoproteins of nonimmune origin which interact with different carbohydrates. The precise physiological role of lectins in nature is still unknown, but they have proven to be valuable in a wide variety of applications, including blocking of receptors for many microorganisms. Here, we used lectins with specificity for terminal sialic acid linked to its neighboring saccharide either through an $\alpha(2-3)$ - or an $\alpha(2-6)$ linked glycosidic bond (MAA and SNA, respectively). We found that MAA but not SNA efficiently inhibited the binding of $\mathrm{Ad} 37$ virions to Chang $\mathrm{C}$ cells, showing that the receptor specificity for $\mathrm{Ad} 37$ is an $\alpha(2-3)$-linked sialic acid on Chang $\mathrm{C}$ cells. WGA has an affinity for both $\alpha(2-3)$ - and $\alpha(2-6)$-linked sialic acid. This lectin confirmed the serotype specificity for sialic acid in that it efficiently blocked attachment of Ad37, but not Ad5, to Chang $\mathrm{C}$ cells. Consequently, the ability of adenoviruses to interact with $\alpha(2-3)$-linked sialic acid on Chang $\mathrm{C}$ cells appears to be limited to Ad37 virions in this study.

To further elucidate the role of sialic acid as a receptor for Ad37 on Chang C cells, we incubated Ad37 virions with sialoconjugates such as sialic acid monosaccharides, sialylated oligosaccharides, and glycoproteins and compared the inhibitory effect of these components on Ad37 attachment with sialic acid-free equivalents. All sialic acid-containing components efficiently inhibited attachment, whereas nonsialylated components failed to do so. Thus, the ability of Ad37 to attach to Chang $\mathrm{C}$ cells was inhibited by removing cell surface sialic acid enzymatically, by blocking cell surface sialic acid with lectins, or by preincubating Ad37 with different types of sialoconjugates, strongly indicating that sialic acid is the major attachment site for Ad37 on Chang C cells.

Recently, Wu et al. (37) proposed that Ad37 infects Chang $\mathrm{C}$ cells via a sialic acid-independent pathway, involving a 50$\mathrm{kDa}$ protein. In our fluorescent focus assay, neuraminidase treatment efficiently protected these cells, as well as two other genital cell lines (HeLa and $\mathrm{SiHa}$ ) and a corneal (HCE) cell line, from being infected by Ad37. This clearly demonstrates the role of sialic acid as a functional receptor for Ad37 on genital cells as well as on corneal cells. Ad5 was not dependent on sialic acid for infection of host cells. Instead, enzymatic removal of sialic acid enhanced the number of infected Chang C, HeLa, SiHa, and HCE cells twofold, thus corroborating the studies using A549 cells (5). Arcasoy et al. (3) previously explained similar results as a consequence of the loss of chargedependent repulsions between the negatively charged Ad5 capsid and the negatively charged (sialylated) cell surface.

Adenovirus-associated EKC is clinically characterized by a severe bilateral conjunctivitis with substantial corneal involve- 

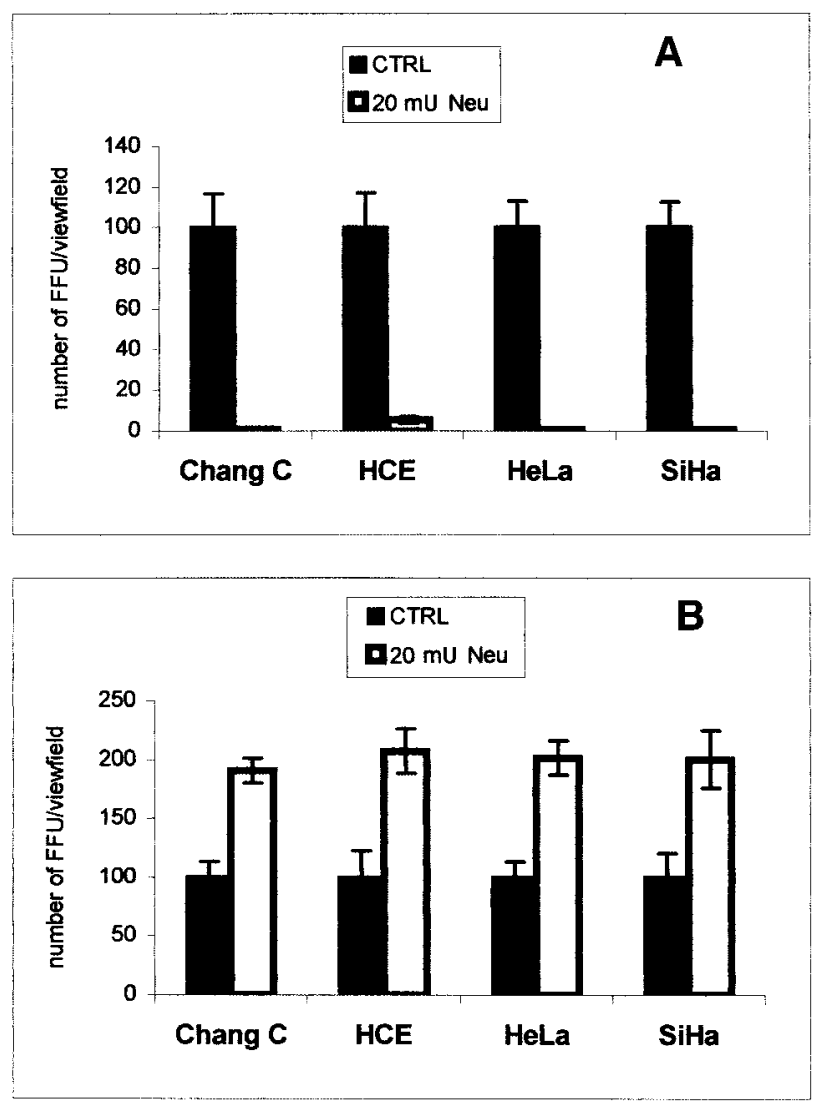

FIG. 6. Neuraminidase treatment of genital (Chang C, HeLa, $\mathrm{SiHa}$ ) and corneal (HCE) cells protects from infection by Ad37 (A) but not by Ad5 (B). Adherent cells were preincubated with or without neuraminidase and then with virion dilutions corresponding to $5,000 \mathrm{FFU} / \mathrm{sample}$, permitting attachment to cells but not internalization. Thus, the virion dilutions were adjusted in order to obtain 100 FFU/viewing field in the control wells (nontreated cells). Then, unbound virions were removed by washing and incubated at $37^{\circ} \mathrm{C}$, thus permitting internalization of virions in cells. At $40 \mathrm{~h}$ postinfection, the cells were rinsed, fixed, stained, and examined in an immunofluorescence microscope (C) as described in Materials and Methods. The results are presented as the means from three independent experiments. CTRL, control.

\section{Chang C}

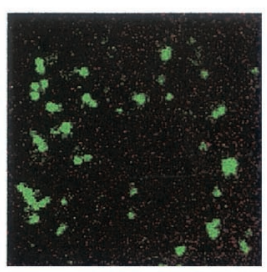

Ad37

- Neu

Ad37

+ Neu
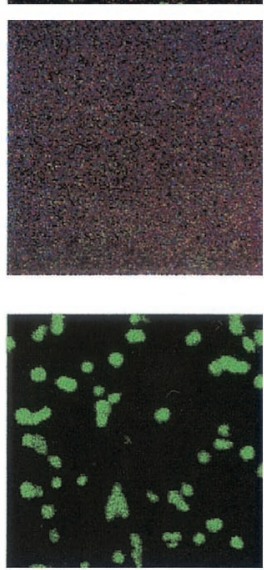

Ad5

- Neu

Ad5

\section{HCE}
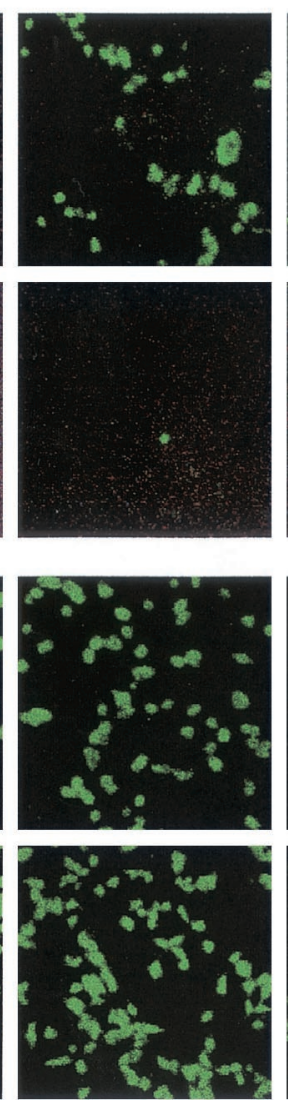

HeLa
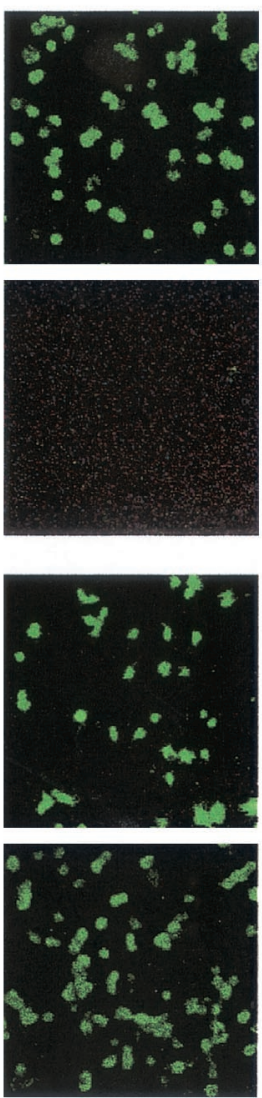

C SiHa
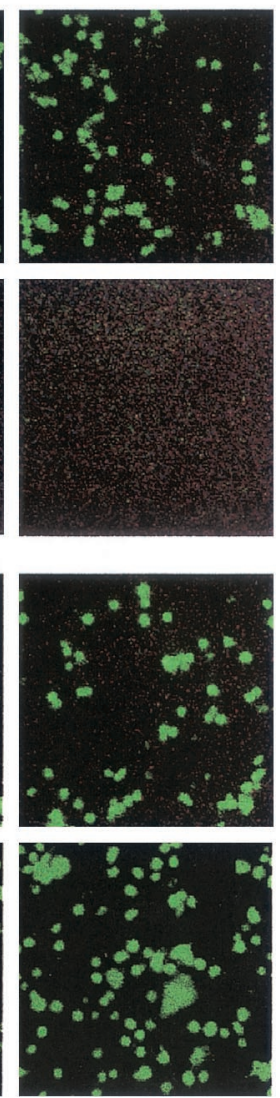
ment. A superficial erosion of the cornea occasionally develops, which, together with infiltration of inflammatory cells, may cause blurring of vision persisting for months or even years $(18$, 19). Since no licensed antiviral agent against this disease is available, there is a need for such a drug. It has been previously shown that the three adenoviruses responsible for the large majority of EKC cases (Ad8, Ad19a, and Ad37) use the same cellular receptor (i.e., sialic acid [4]). Consequently, sialic acid may serve as a very attractive drug target. In contradiction to the findings of Wu et al. (37), our study clearly shows that sialic acid is the major receptor for Ad37 on Chang C cells as well as on cells originating from the primary target organ for Ad37, the cornea.

\section{ACKNOWLEDGMENTS}

We thank Elisabeth Jansson of the Swedish Institute for Infectious Disease Control, Stockholm, Sweden, for kindly providing Chang C cells and Kaoro Araki-Sasaki, Kinki Central Hospital, Itami City, Hyogo, Japan, for kindly providing HCE cells.

This work has been supported by grant K2001-99XG-13281-03C from the Swedish Medical Research Council.

\section{REFERENCES}

1. Adrian, T., G. Wadell, J. C. Hierholzer, and R. Wigand. 1986. DNA restriction analysis of adenovirus prototypes 1 to 41. Arch. Virol. 91:277-290.

2. Araki-Sasaki, K., K. Y. Ohasi, T. Sasabe, K. Hayashi, H. Watanabe, Y. Tano, and H. Handa. 1995. An SV-40-immortalized human corneal epithelial cell line and its characterization. Investig. Ophthalmol. 36:614-621.

3. Arcasoy, S. M., J. Latoche, M. Gondor, S. C. Watkins, R. A. Henderson, R. Hughey, O. J. Finn, and J. M. Pilewski. 1997. MUC1 and other sialoglycoconjugates inhibit adenovirus-mediated gene transfer to epithelial cells. Am. J. Respir. Cell Mol. Biol. 17:422-435.

4. Arnberg, N., A. H. Kidd, K. Edlund, F. Olfat, and G. Wadell. 2000. Initial interactions of subgenus D adenoviruses with A549 cellular receptors: sialic acid versus $\alpha_{\mathrm{v}}$ integrins. J. Virol. 74:7691-7693.

5. Arnberg, N., K. Edlund, A. H. Kidd, and G. Wadell. 2000. Adenovirus type 37 uses sialic acid as a cellular receptor. J. Virol. 74:42-48.

6. Arnberg, N., Y. Mei, and G. Wadell. 1997. Fiber genes of adenoviruses with tropism for the eye and the genital tract. Virology 227:239-244.

7. Azar, M. J., D. K. Dhaliwal, K. S. Bower, R. P. Kowalski, and Y. J. Gordon. 1996. Possible consequences of shaking hands with your patients with epidemic keratoconjunctivitis. Am. J. Ophthalmol. 121:711-712.

8. Bell, S. D., T. Rondon Rota, and D. E. McComb. 1960. Adenoviruses isolated from Saudi Arabia. III. Six new serotypes. J. Trop. Med. Hyg. 9:523-526.

9. Benkö, M., B. Harrach, and W. C. Russell. 2000. Family Adenoviridae, p. 227-238. In M. V. H. van Regenmortel, C. M. Fauquet, and D. H. L. Bishop (ed.), Virus taxonomy. Academic Press, New York, N.Y.

10. Bergelson, J. M., J. A. Cunningham, G. Droguett, E. A. Kurt-Jones, A Krithivas, J. S. Hong, M. S. Horwitz, R. L. Crowell, and R. W. Finberg. 1997. Isolation of a common receptor for coxsackie B viruses and adenoviruses 2 and 5. Science 275:1320-1323.

11. Bewley, M. C., K. Springer, Y. B. Zhang, P. Freimuth, and J. M. Flanagan. 1999. Structural analysis of the mechanism of adenovirus binding to its human cellular receptor, CAR. Science 286:1579-1583.

12. Chu, Y., D. Heistad, M. I. Cybulsky, and B. L. Davidson. 2001. Vascular cell adhesion molecule-1 augments adenovirus-mediated gene transfer. Arterioscler. Thromb. Vasc. Biol. 21:238-242.

13. Dechecchi, M. C., A. Tamanini, A. Bonizzato, and G. Cabrini. 2000. Heparan sulfate glycosaminoglycans are involved in adenovirus type 5 and 2-host cell interactions. Virology 268:382-390.

14. Dechecchi, M. C., P. Melotti, A. Bonizzato, M. Santacatterina, M. Chilosi, and G. Cabrini. 2001. Heparan sulfate glycosaminoglycans are receptors sufficient to mediate initial binding of adenovirus types 2 and 5. J. Virol. 75:8772-8780.

15. Defer, C., M.-T. Belin, M.-L. Caillet-Boudin, and P. Boulanger. 1990. Human adenovirus-host cell interactions: comparative study with members of subgroups B and C. J. Virol. 64:3661-3673.
16. De Jong, J. C., A. G. Wermenbol, M. W. Verweij-Uijterwaal, K. W. Slaterus, P. Wertheim-Van Dillen, G. J. Van Doornum, S. H. Khoo, and J. C. Hierholzer. 1999. Adenoviruses from human immunodeficiency virus-infected individuals, including two strains that represent new candidate serotypes Ad50 and Ad51 of species B1 and D, respectively. J. Clin. Microbiol. 37: 3940-3945.

17. De Jong, J. C., R. Wigand, G. Wadell, D. Keller, C. J. Muzerie, A. G. Wermenbol, and G. J. Schaap. 1981. Adenovirus 37: identification and characterization of a medically important new adenovirus type of subgroup D. J. Med. Virol. 7:105-118.

18. Ford, E., K. E. Nelson, and D. Warren. 1987. Epidemiology of epidemic keratoconjunctivitis. Epidemiol. Rev. 9:244-261.

18a.Gall, J., A. Kass-Eisler, L. Leinwand, and E. Falck-Pedersen. 1996. Adenovirus type 5 and 7 capsid chimera: fiber replacement alters receptor tropism without affecting primary immune neutralizing epitopes. J. Virol. 70:21162123.

19. Gordon, Y. J., K. Aoki, and P. R. Kinchington. 1996. Adenovirus keratoconjunctivitis, p. 877-894. In J. S. Pepose, G. N. Holland, and K. R. Wilhelmus (ed.), Ocular infection and immunity. C.V. Mosby, St. Louis, Mo.

20. Hierholzer, J. C., B. Guyer, D. O'Day, and W. Schaffner. 1974. Adenovirus type 19 keratoconjunctivitis. N. Engl. J. Med. 290:1436.

21. Hong, S. S., L. Karayan, J. Tournier, D. T. Curiel, and P. A. Boulanger. 1997. Adenovirus type 5 fiber knob binds to MHC class I alpha2 domain at the surface of human epithelial and B lymphoblastoid cells. EMBO J. 16:22942306.

22. Huang, S., V. Reddy, N. Dasgupta, and G. R. Nemerow. 1999. A single amino acid in the adenovirus type 37 fiber confers binding to human conjunctival cells. J. Virol. 73:2798-2802.

23. Jawetz, E., A. Kimura, N. Nicholas, P. Thygeson, and L. Hanna. 1955. New type of APC virus from keratoconjunctivitis. Science 122:1190-1192.

24. Kirby, I., R. Lord, E. Davison, T. J. Wickham, P. W. Roelwink, I. Kovesdi, B. J. Sutton, and G. Santis. 2001. Adenovirus type 9 fiber knob binds to the coxsackie B virus-adenovirus receptor (CAR) with lower affinity than fiber knobs of other CAR-binding adenovirus serotypes. J. Virol. 75:7210-7214.

25. Phillips, P. A., G. B. Harnett, and M. M. Gollow. 1982. Adenovirus type 19 and a closely related new serotype in genital infection. Br. J. Vener. Dis. 58:131-132.

26. Pring-Åkerblom, P., A. Heim, and F. E. J. Trijssenaar. 1998. Molecular characterization of hemagglutination domains on the fibers of subgenus D adenoviruses. J. Virol. 72:2297-2304.

27. Roelvink, P. W., A. Lizonova, J. G. Lee, Y. Li, J. M. Bergelson, R. W. Finberg, D. E. Brough, I. Kovesdi, and T. J. Wickham. 1998. The coxsackievirusadenovirus receptor protein can function as a cellular attachment protein for adenovirus serotypes from subgroups A, C, D, E, and F. J. Virol. 72:79097915.

28. Roelvink, P. W., G. Mi Lee, D. A. Einfeld, I. Kovesdi, and T. J. Wickham. 1999. Identification of a conserved receptor-binding site on the fiber proteins of CAR-recognizing adenoviridae. Science 286:1568-1571.

29. Shayakhmetov, D. M., and A. Lieber. 2000. Dependence of adenovirus infectivity on length of the fiber shaft domain. J. Virol. 74:10274-10286.

30. Shenk, T. 1996. Adenoviridae: the viruses and their replication, p. 21112148. In B. N. Fields, D. M. Knipe, and P. M. Howley (ed.), Fields virology. Lippincott-Raven Publishers, Philadelphia, Pa.

31. Swenson, P. D., M. S. Lowens, C. L. Celum, and J. C. Hierholzer. 1995 Adenovirus types 2, 8, and 37 associated with genital infections in patients attending a sexually transmitted disease clinic. J. Clin. Microbiol. 33:27282731.

32. Tomko, R. P., R. Xu, and L. Philipson. 1997. HCAR and MCAR: the human and mouse cellular receptors for subgroup $\mathrm{C}$ adenoviruses and group $\mathrm{B}$ coxsackieviruses. Proc. Natl. Acad. Sci. USA 94:3352-3356.

33. Wadell, G. 1984. Molecular epidemiology of human adenoviruses. Curr. Top. Microbiol. Immunol. 110:191-220.

34. Wadell, G., A. Allard, and J. C. Hierholzer. 1999. Adenoviruses, p. 970-982. In P. R. Murray, E. J. Baron, M. A. Pfaller, F. C. Tenover, and R. H. Yolken (ed.), Manual of clinical microbiology, 7th ed. ASM Press, Washington, D.C.

35. Wadell, G., and J. C. de Jong. 1980. Restriction endonucleases in identification of a genome type of adenovirus 19 associated with keratoconjunctivitis. Infect. Immun. 27:292-296.

36. Wadell, G., M.-L. Hammarskjöld, G. Winberg, M. Varsanyi, and G. Sundell. 1980. Genetic variability of adenoviruses. Ann. N. Y. Acad. Sci. 354:16-42.

37. Wu, E., J. Fernandez, S. K. Fleck, D. J. Von Seggern, S. Huang, and G. R. Nemerow. 2001. A 50-kDa membrane protein mediates sialic acid-independent binding and infection of conjunctival cells by adenovirus type 37 . Virology 279:78-89. 